RECURSOS HUMANOS 


\title{
ROTATIVIDADE: ANÁLISE DE VINTE ANOS DA PRODUÇÃO CIENTÍFICA BRASILEIRA
}

\author{
TURNOVER: ANALYZING TWENTY YEARS OF THE BRAZILIAN \\ SCIENTIFIC PRODUCTION
}

Juliana Seidl

Universidade de Brasília

Jairo Eduardo Borges-Andrade

Instituto de Psicologia da Universidade de Brasília

Elaine Rabelo Neiva

Instituto de Psicologia da Universidade de Brasília
Data de submissão: 19 abr. 20 | 8. Data de aprovação:

20 set. 2018 . Sistema de avaliação: Double blind review.

Universidade FUMEC / FACE. Prof. Dr. Henrique Cordeiro

Martins. Prof. Dr. Cid Gonçalves Filho.

\section{RESUMO}

A rotatividade de pessoal é um fenômeno multicausal e natural nas organizações, porém, em altas taxas, pode ocasionar prejuízos à sustentabilidade financeira e à memória institucional. Objetivou-se analisar a produção científica empírica brasileira sobre rotatividade de pessoal nas organizações de 1996 a 2015. Foram consultados periódicos com tradição nas áreas organizacional e do trabalho; em seguida, ampliou-se a busca. Foram selecionados artigos empíricos que apresentassem pelo menos um dos descritores no título e/ou nas palavras-chave: rotatividade, intenção de saída, desligamento e/ou turnover.Vinte e cinco artigos foram analisados segundo aspectos bibliométricos, metodológicos, antecedentes, objetivos e principais resultados. As pesquisas brasileiras sobre o tema são recentes, na maioria descritivas, publicadas em revistas da administração e visam conhecer os fatores organizacionais e do trabalho que influenciam a rotatividade. Sugere-se que estudos futuros investiguem também fatores antecedentes pessoais e ambientais, seus consequentes, por meio do uso de métodos multivariados.

\section{PALAVRAS-CHAVE}

Rotatividade. Intenção de Saída. Revisão da Literatura. Comportamento Organizacional. Produção Científica Brasileira. 


\section{ABSTRACT}

Personnel turnover is a multicausal and natural phenomena in organizations, but at high rates it can cause damage to financial sustainability and to the institutional memory. This study aimed to analyze the Brazilian empirical scientific production on personnel turnover in organizations from 1996 to 2015. Brazilian journals with tradition in the organizational and work areas were consulted; and then the search was broadened. The empirical articles selected presented at least one of the expressions in the title and/or in the keywords: turnover, intention of exit andlor detachment. Twenty-five articles were analyzed according to bibliometric, methodological, turnover antecedents, objectives and main results. Brazilian studies on the subject are recent, mostly descriptive, published in business journals and investigated especially organizational and work factors that influence turnover. Future studies could then analyze personal and environmental antecedents, as well as consequent factors, through the adoption of multivariate analyses.

\section{KEYWORDS}

Turnover. Intention to Leave. Literature Review. Organizational Behavior. Brazilian Scientific Production.

\section{INTRODUÇÃO}

A economia brasileira tem sido caracterizada como menos competitiva, se comparada com a de outros países emergentes, porque o aumento de salários e encargos (renda do trabalho) não foi acompanhado do aumento da produtividade - definida como a quantidade de bens e serviços produzidos por hora de trabalho - nos últimos anos no Brasil (NERY, 20I5). Segundo o economista Pedro Fernando Nery, a elevada rotatividade é citada como uma das principais barreiras ao crescimento da produtividade e, consequentemente, da economia brasileira.

Enquanto em países europeus, como Alemanha e França, o tempo médio no emprego é de cerca de 12 anos, no Brasil é de 5 anos, segundo dados do Departamento Intersindical de Estatística e Estu- dos Socioeconômicos (DIEESE, 20I4). Em um estudo conduzido por diferentes organismos internacionais que comparou níveis e características da rotatividade na União Europeia, Estados Unidos, Japão e Brasil, observou-se que as taxa de rotatividade entre empregados brasileiros com até três meses de trabalho chega a ser de duas a cinco vezes superiores à praticada nos demais países.Além disso, identificou-se nesta pesquisa que os brasileiros que enfrentam maior rotatividade são homens, jovens, e trabalham em empregos que exigem menor escolaridade (POCHMANN, 2009).

Desde meados do século $X X$ até a última década, a literatura internacional busca responder acerca do que leva as pessoas a optar por sair do local onde trabalham: se são as precárias condições de trabalho que as estimulam a deixar a organização, 
se são as aspirações pessoais que as motivam a buscar novas oportunidades, ou se seria uma combinação das duas situações. Além disso, no nível organizacional, pesquisas têm se debruçado para averiguar se as estratégias adotadas para redução da rotatividade são as mesmas para o estímulo à retenção de pessoal bem como quais são os efeitos da rotatividade para as equipes e para as organizações (BRAYFIELD; CROCKETT, 1955; HOM et al., 20 17).

$\mathrm{E}$ no caso das pesquisas sobre rotatividade no Brasil? Quais métodos de pesquisa têm sido utilizados? Em quais revistas os artigos têm sido publicados? Quais objetivos têm norteado os estudos e quais resultados têm sido observados? Com base nessas perguntas, o objetivo desta revisão da literatura foi analisar a produção científica empírica brasileira sobre rotatividade nas organizações no período de vinte anos: 1996 a 2015.

Nas próximas linhas, o conceito de rotatividade e a trajetória histórica do seu estudo no contexto internacional serão apresentados. Em seguida, na seção método, o leitor terá acesso aos critérios utilizados para identificação dos artigos desta revisão. Os resultados versam sobre a caracterização bibliométrica e a análise de conteúdo das publicações, no que se refere a aspectos metodológicos, antecedentes, objetivos e principais resultados. Por fim, a discussão cotejará o caminhar dos estudos sobre o tema no Brasil em relação às publicações internacionais, destacando também as limitações desta revisão e a indicação de estudos futuros.

\section{ROTATIVIDADE: DEFINIÇÃO ETRAJETÓRIA}

Turnover pode ser definido como a razão entre o número de empregados que deixaram a organização em determinado período e o número de empregados que ingressaram (PRICE, 1977; HARKINS, 1998). O termo é usado frequentemente como sinônimo de demissão voluntária, planejada pelo trabalhador, mas alguns estudos também aplicam esse termo à demissão involuntária, provocada pela organização (ONGORI, 2007; ROBBINS et al., 20 I0).

Muitas vezes os estudos sobre o tema não se referem ao comportamento de saída da organização em si, mas à intenção de saída também. Há evidências empíricas que mostram que a intenção comportamental de saída ou de permanência é um preditor significativo da rotatividade de pessoal (STEEL; LOUNSBURY, 2009). Logo, ter acesso aos motivos que levam às intenções de rotatividade também sinaliza aos gestores a necessidade de desenvolver ações capazes de evitar o afastamento definitivo dos profissionais da organização.

As primeiras publicações que se referiram ao fenômeno turnover são de 1917 , ano considerado de nascimento das investigações sobre o tema. O período de 1920 a 1970 foi denominado de anos formativos. Fortes evidências da relação entre absenteísmo e rotatividade foram encontradas por Brayfield e Crockett (1955) e Herzberg et al. (1959). De acordo com a revisão publicada por Hom et al. (2017), a década de 1970 foi denominada de modelos fundadores já que teorias e modelos começaram a ser construídos.

A década seguinte foi intitulada testagem da teoria e a de 1990 foi denominada de unfolding model, quando Lee e Mitchell (1994) propuseram modelo de desdobramento de rotatividade voluntária, que descreve diferentes caminhos psicológicos 
feitos pelo indivíduo durante o processo de tomada de decisão de desligamento. $O$ período compreendido entre o ano 2000 até os dias atuais foi designado pesquisa do século $X X I$ sobre rotatividade, período em que meta-análises sobre os antecedentes começaram a ser publicadas, o construto job embeddedness passou a ser incorporado e a literatura sobre turnover coletivo começou a emergir (HEAVEY et al., 20I3).

Nesses cem anos, a rotatividade foi exaustivamente investigada internacionalmente e uma ampla quantidade de fatores foi identificada como antecedentes (KEVIN et al., 2004; ONGORI, 2007; HOM et al., 2017).Variáveis disposicionais (e.g. atitudes, satisfação no trabalho e comprometimento organizacional), intenções para ficar ou sair da organização e a percepção de que há alternativas e oportunidades de emprego no mercado de trabalho têm se apresentado há anos como variáveis centrais dos modelos de investigação sobre o processo de rotatividade (STEEL; LOUNSBURY, 2009). Um dos primeiros e mais conhecidos estudos demonstrou uma relação negativa consistente entre satisfação no trabalho e intenção de rotatividade, por exemplo (VROOM, 1964 apud STEEL; LOUNSBURY, 2009).

Traços de personalidade, valores, idade, tempo na organização, habilidades, treinamento, profissionalismo e responsabilidades familiares representam construtos pessoais e familiares investigados em pesquisas internacionais sobre o tema. Já conflito e ambiguidade de papéis, falta de reconhecimento, má remuneração (salários e benefícios), sobrecarga e/ou estresse gerados pelo trabalho e pouca abertura no processo de comunicação da organização expressam fatores organizacionais e do trabalho bastante estudados (ONGORI, 2007; HOM et al.,
2017). Além desses fatores, mecanismos de mudanças internas e externas se configuram como mais um grupo de construtos investigados como preditores da rotatividade, a saber: desejo de mudança, expectativas em relação a empregos futuros, possibilidade de promoção intraorganizacional, chance de demissão ou outras formas de desligamento (STEEL; LOUNSBURY, 2009).

\section{MÉTODO}

Uma revisão da literatura foi conduzida, incluindo artigos publicados entre janeiro de 1996 a dezembro de 2015, totalizando vinte anos. Uma das categorias das revisões de comportamento organizacional (CO) publicadas pelo periódico Annual Review of Psychology é comportamento de fuga e esquiva no trabalho e uma de suas subcategorias é intenções ou ações relacionadas à rotatividade, tema de interesse do presente estudo.

Optou-se, na primeira etapa do processo de revisão, filtrar todos os artigos que tivessem os descritores rotatividade, intenção de saída, desligamento e/ou turnover no título e/ou nas palavras-chave. Em um segundo momento, foram incorporados outros critérios de inclusão: o estudo deveria ser empírico e pelo menos parte da amostra deveria ser composta por trabaIhadores brasileiros.

Inicialmente, foram consultados 17 periódicos nacionais, sendo sete da administração: I. Brazilian Administration Review (BAR); 2. Organização \& Sociedade (O\&S); 3. Revista de Administração Contemporânea (RAC); 4. Revista de Administração da Universidade de São Paulo (RAUSP); 5. Revista de Administração de Empresas (RAE); 6. Revista de Administração Mackenzie (RAM); 7. Revista de Administração Pública (RAP); e dez da psicologia: I. Avaliação Psicológica; 2. Estudos 
de Psicologia (Natal); 3. Estudos de Psicologia (Campinas); 4. Psicologia, Ciência e Profissão; 5. Psicologia em Estudo; 6. Psicologia: Organizações e Trabalho (rPOT); 7. Psico; 8. Psico - USF; 9. Psicologia: Reflexão e Crítica; e 10. Psicologia:Teoria e Pesquisa.A escolha desses periódicos deveu-se à tradição deles em publicar artigos das áreas organizacional e do trabalho, bem como por aspectos de indexação e suas avaliações em nível nacional pelo Qualis da Coordenação de Aperfeiçoamento de Pessoal de Nível Superior (CAPES), nas respectivas áreas de concentração (Psicologia e Administração), variando de $\mathrm{Al}$ a BI.

No período de 1996 a 2015, foram encontrados II artigos nos periódicos mencionados que atendiam aos critérios de inclusão. Decidiu-se, então, ampliar a pesquisa e realizar uma nova busca de artigos no Google Acadêmico/Google Scholar, para localizar publicações em outros periódicos brasileiros. Os artigos selecionados deveriam conter os mesmos descritores no título e/ou nas palavras-chave, respeitando os mesmos critérios de inclusão previa- mente estabelecidos. Nesta segunda rodada, foram identificados mais 14 artigos.

Destaca-se que uma dupla formada por docente e/ou discente da pós-graduação - devidamente treinada para a aplicação dos procedimentos de busca - realizou a pesquisa e, a posteriori, outra dupla de pesquisadores refez a busca, conferindo se a seleção inicial havia sido conduzida adequadamente. Logo, a presente revisão da literatura incluiu 25 publicações sobre o tema. Procedeu-se, então, à leitura na íntegra desses artigos, tendo em vista a descrição bibliométrica, aspectos metodológicos, a identificação de variáveis antecedentes/ motivos da rotatividade bem como seus objetivos e resultados principais.

\section{RESULTADOS}

A quantidade de artigos empíricos sobre o tema intenções ou ações relacionadas à rotatividade tem crescido no Brasil, já que sete artigos foram publicados nos três primeiros quadriênios e 18 (72\%) nos dois últimos, de 2008 a 2015 , como mostra a Figura I.

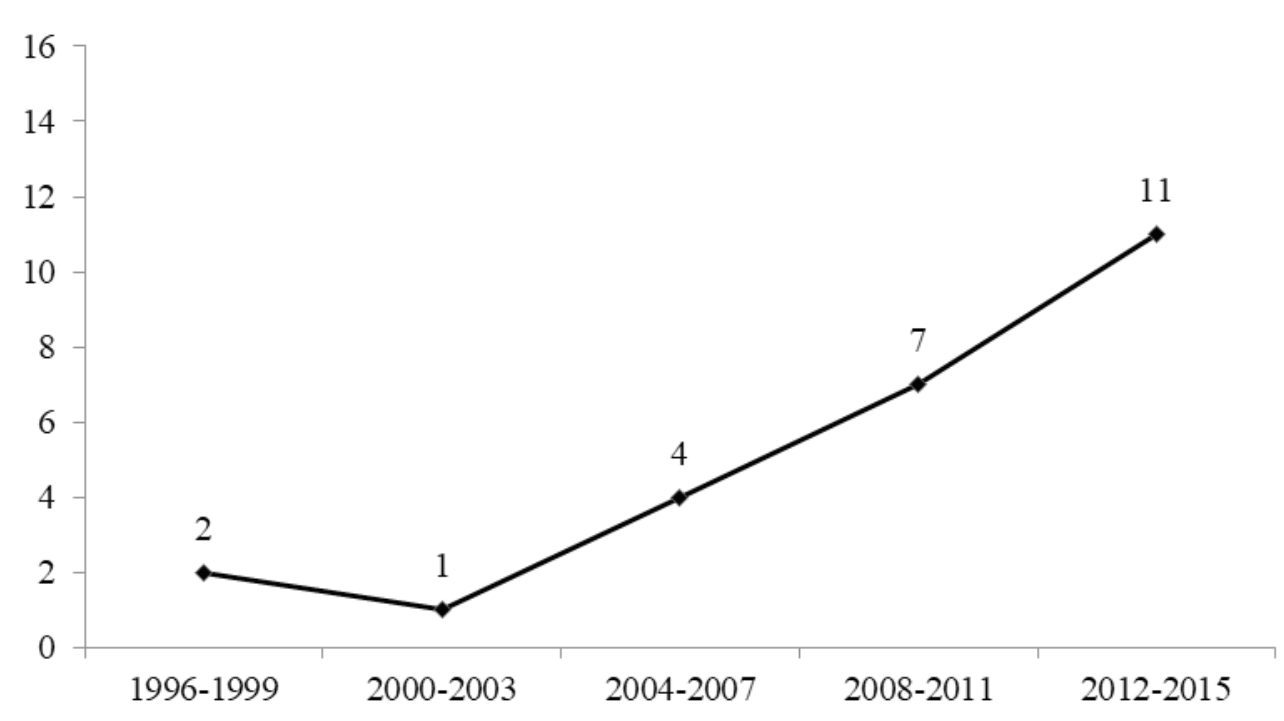

FIGURA 1 - Quantidade de artigos nacionais sobre rotatividade de 1996 a 2015 
Observa-se que o tema tem sido especialmente publicado no Brasil em duas grandes áreas: administração e saúde/enfermagem (vide Tabela I). Dos 25 artigos encontrados, 16 deles foram publicados em periódicos de administração/gestão, oito em periódicos da saúde/enfermagem e apenas um em periódico multidisciplinar. O periódico com maior número de publicações foi a Revista de Administração Contemporânea (RAC), com três artigos, sendo que a grande maioria dos periódicos publicou um único estudo sobre o assunto nesses 20 anos. Não foram identificados artigos nos periódicos de psicologia sobre o tema no período do levantamento.

A Tabela 2 apresenta uma análise dos artigos quanto aos aspectos metodológicos e delineamentos adotados. $O$ delineamento mais comum da pesquisa nacional em rotatividade tem sido a quantitativa. A maioria dos estudos colheu dados provenientes de várias organizações e a origem deles foi predominantemente primária. Quanto aos tipos de instrumentos, os questionários foram os mais comumente adotados, seguida da análise documental já que alguns pesquisadores fazem uso dos registros feitos pelas organizações sobre a saída dos seus trabalhadores.

A quantidade de estudos inferenciais é mais elevada, porém próxima da quantidade de descritivos numéricos. $\bigcirc$ segmento mais investigado foi o terciário e, no que se refere ao setor das organizações, observou-se que os estudos nacionais sobre rotatividade investigaram mais o setor privado.

Os Quadros I e 2 caracterizam os 25 artigos encontrados quanto ao ano de publicação, autores, delineamento, objetivos e principais resultados, sendo que o Quadro I se refere aos artigos da saúde/enfermagem e multidisciplinar e o 2 às publicações e administração/gestão. Dos sete artigos

TABELA 1 - Periódicos científicos em que os artigos foram publicados ( $N=25)$

\begin{tabular}{|c|c|c|}
\hline Área & Periódicos & Quantidade \\
\hline \multirow{7}{*}{$\begin{array}{c}\text { Enfermagem/ } \\
\text { Saúde }\end{array}$} & Ciência \& Saúde Coletiva & 1 \\
\hline & Revista Brasileira de Enfermagem & 1 \\
\hline & Revista Gaúcha de Enfermagem & 1 \\
\hline & Revista Panamericana de Salud Pública & 1 \\
\hline & Revista Trabalho, Educação e Saúde & 1 \\
\hline & Saúde em Debate & 1 \\
\hline & Revista Latino-americana de Enfermagem & 2 \\
\hline \multirow{13}{*}{$\begin{array}{c}\text { Administração/ } \\
\text { Gestão }\end{array}$} & Brazilian Administration Review & 1 \\
\hline & Gestão \& Planejamento & 1 \\
\hline & Revista de Administração IMED & 1 \\
\hline & Organização \& Sociedade & 1 \\
\hline & Organização em Contexto & 1 \\
\hline & Revista de Administração, Contabilidade e Economia & 1 \\
\hline & Revista de Administração de Empresas & 1 \\
\hline & Revista de Administração Mackenzie & 1 \\
\hline & Revista de Administração Pública & 1 \\
\hline & Revista de Administração da UFSM & 1 \\
\hline & Revista de Ciências Gerenciais & 1 \\
\hline & Revista de Administração da Universidade de São Paulo & 2 \\
\hline & Revista de Administração Contemporânea & 3 \\
\hline \multirow[t]{2}{*}{ Multidisciplinar } & Novos Estudos (CEBRAP) & 1 \\
\hline & & 25 \\
\hline
\end{tabular}

Fonte: Elaborado pelos autores. 
TABELA 2 - Classificação dos artigos sobre rotatividade $(\mathbf{N}=25)$

\begin{tabular}{|c|c|c|}
\hline Critérios de classificação & Quantidade & Percentual \\
\hline \multicolumn{3}{|l|}{ Natureza da pesquisa } \\
\hline Quantitativa & 17 & 68,00 \\
\hline Quali-quanti & 5 & 20,00 \\
\hline Qualitativa & 3 & 12,00 \\
\hline \multicolumn{3}{|l|}{ Natureza da amostragem } \\
\hline Várias organizações & 17 & 68,00 \\
\hline Uma organização & 8 & 32,00 \\
\hline \multicolumn{3}{|l|}{ Origem dos dados } \\
\hline Primária & 15 & 60,00 \\
\hline Secundária & 09 & 36,00 \\
\hline Primária e secundária & 01 & 4,00 \\
\hline \multicolumn{3}{|l|}{ Tipos de instrumento* } \\
\hline Questionário/Escala & 14 & 45,16 \\
\hline Análise de documento & 10 & 32,26 \\
\hline Entrevista & 06 & 19,35 \\
\hline Observação & 01 & 3,23 \\
\hline \multicolumn{3}{|l|}{ Procedimentos de análise de dados } \\
\hline Inferencial & 11 & 44,00 \\
\hline Estatística descritiva & 09 & 36,00 \\
\hline Análise de conteúdo (descritivo) & 05 & 20,00 \\
\hline \multicolumn{3}{|l|}{ Segmento da economia } \\
\hline Terciário (serviços) & 17 & 68,00 \\
\hline Secundário (indústria) & 02 & 8,00 \\
\hline Primário (agricultura) & 0 & 0,00 \\
\hline Diversos & 03 & 12,00 \\
\hline Não informou & 03 & 12,00 \\
\hline \multicolumn{3}{|l|}{ Setor estudado } \\
\hline Privado & 11 & 44,00 \\
\hline Público & 07 & 28,00 \\
\hline Terceiro setor & 01 & 4,00 \\
\hline Misto (2 ou mais setores) & 06 & 24,00 \\
\hline
\end{tabular}

${ }^{*}$ Apenas esta categoria ultrapassa 25 já que alguns estudos adotaram mais de um instrumento

Fonte: Elaborado pelos autores.

publicados até 2007 , apenas um teve como objetivo a testagem de um modelo (FERREIRA; SIQUEIRA, 2005). Já de 2008 a 20I5, dez artigos sobre o tema utilizaram técnicas inferenciais, indicando que a adoção de análises estatísticas multivariadas é recente.

Entre os oito artigos publicados em revistas de enfermagem/saúde, sete eram descritivos numéricos. Apenas uma análise de conteúdo foi realizada e as informações obtidas foram sistematizadas para identifi- car as razões da rotatividade entre médicos e enfermeiros (MEDEIROS et al., 20 I0). O único estudo publicado em uma revista multidisciplinar também era descritivo. Já entre os 16 estudos identificados em periódicos da área de administração, cinco deles eram descritivos (sendo que quatro utilizaram análise de conteúdo e um adotou estatística descritiva) e II realizaram análises inferenciais dos dados (vide Quadros I e 2). 
QUADRO 1 - Autores, ano, delineamento, objetivos e resultados principais das publicações empíricas sobre rotatividade publicadas em revistas de saúde/enfermagem e multidisciplinar

\begin{tabular}{|c|c|c|c|c|}
\hline $\mathbf{N}^{0}$ & Autor(es) (Ano) & Delineamento & Objetivo(s) & Resultados Principais \\
\hline \multicolumn{5}{|c|}{ Periódicos de Enfermagem/Saúde } \\
\hline 1 & Bezerra (1997) & $\begin{array}{l}\text { Quanti-quali } \\
\text { descritivo }\end{array}$ & $\begin{array}{l}\text { Avaliar a frequência e os motivos } \\
\text { da rotatividade de } 54 \text { enfermeiros } \\
\text { que se desligaram de um hospital } \\
\text { privado de São Paulo (SP). }\end{array}$ & $\begin{array}{c}\text { A carga horária cansativa, a sobrecarga de } \\
\text { serviço, o excesso de burocracias e a falta de } \\
\text { orientação pelas chefias representaram } 54,5 \% \\
\text { dos aspectos que levaram à rotatividade. } \\
74,1 \% \text { dos enfermeiros se desligaram até o } \\
12^{\circ} \text { mês. }\end{array}$ \\
\hline 2 & $\begin{array}{l}\text { Anselmi et al. } \\
\quad(1997)\end{array}$ & $\begin{array}{l}\text { Quantitativo } \\
\text { descritivo }\end{array}$ & $\begin{array}{c}\text { Medir e analisar a rotatividade } \\
\text { dos trabalhadores de } \\
\text { enfermagem alocados em nove } \\
\text { hospitais gerais de Ribeirão Preto } \\
\text { (SP). }\end{array}$ & $\begin{array}{l}\text { Evidenciou-se elevada rotatividade, } \\
\text { principalmente nos hospitais filantrópicos e } \\
\text { privados, com taxas líquidas de substituição } \\
\text { de } 32 \% \text { e } 39 \% \text { ao ano e mediana de } \\
\text { tempo de serviço de } 8 \text { meses e } 12 \text { meses, } \\
\text { respectivamente. O hospital público analisado } \\
\text { apresentou níveis mais baixos, com uma } \\
\text { taxa líquida de substituição de } 6 \% \text { ao ano e } \\
\text { mediana de tempo de serviço de } 42 \text { meses. }\end{array}$ \\
\hline 3 & $\begin{array}{l}\text { Nomura e } \\
\text { Gaidzinski } \\
(2005)\end{array}$ & $\begin{array}{l}\text { Quantitativo } \\
\text { descritivo }\end{array}$ & $\begin{array}{l}\text { Analisar razões de desligamento } \\
\text { e taxas de rotatividade da equipe } \\
\text { de enfermagem de hospital } \\
\text { universitário da cidade de São } \\
\text { Paulo }\end{array}$ & $\begin{array}{c}\text { Dos } 255 \text { profissionais de enfermagem } \\
\text { que se desligaram, } 103 \text { foram demitidos } \\
\text { sem justa causa; um por justa causa; } 26 \\
\text { se aposentaram; quatro faleceram e } 121 \\
\text { solicitaram demissão. Os autores concluíram } \\
\text { que a equipe de enfermagem, nesse hospital } \\
\text { apresentava baixa rotatividade. }\end{array}$ \\
\hline 4 & $\begin{array}{c}\text { Holanda e } \\
\text { Cunha (2005) }\end{array}$ & $\begin{array}{l}\text { Quantitativo } \\
\text { descritivo }\end{array}$ & $\begin{array}{l}\text { Conhecer o tempo de } \\
\text { permanência de } 109 \text { enfermeiros } \\
\text { que se desligaram de uma } \\
\text { instituição hospitalar e sua } \\
\text { relação com o valor monetário } \\
\text { em horas/salário referente } \\
\text { à admissão, à saída e ao } \\
\text { provimento de novo enfermeiro. }\end{array}$ & $\begin{array}{l}\text { O tempo de permanência foi curto (média } \\
\text { de } 20 \text { meses e mediana } 18 \text { ); } 30,53 \% \text { dos } \\
\text { enfermeiros deixaram o hospital com menos } \\
\text { de um ano; o valor monetário médio para } \\
\text { admissão e desligamento foi de } \mathrm{R} \$ 881,43 \text { e o } \\
\text { tempo de permanência breve duplicou o custo } \\
\text { para a contratação de um novo profissional. }\end{array}$ \\
\hline 5 & $\begin{array}{c}\text { Iwamoto e } \\
\text { Anselmi (2006) }\end{array}$ & $\begin{array}{l}\text { Quantitativo } \\
\text { descritivo }\end{array}$ & $\begin{array}{l}\text { Descrever a rotatividade de } 276 \\
\text { trabalhadores de enfermagem em } \\
11 \text { hospitais de Uberaba (MG). }\end{array}$ & $\begin{array}{l}\text { A taxa de admissão dos trabalhadores foi } \\
\text { superior à de desligamento, exceto para } \\
\text { auxiliares de enfermagem; a taxa líquida } \\
\text { de substituição foi de } 24,3 \% \text {, e o quadro de } \\
\text { trabalhadores seria totalmente renovado } \\
\text { no prazo de } 3,6 \text { anos. Identificou-se maior } \\
\text { estabilidade e menor rotatividade dos } \\
\text { trabalhadores de hospital público e maior } \\
\text { rotatividade nos hospitais privados. }\end{array}$ \\
\hline 6 & $\begin{array}{l}\text { Medeiros et al. } \\
\qquad(2010)\end{array}$ & $\begin{array}{c}\text { Quanti-quali } \\
\text { descritivo }\end{array}$ & $\begin{array}{l}\text { Analisar as causas do índice } \\
\text { de rotatividade de médicos e } \\
\text { enfermeiros das equipes da } \\
\text { Estratégia de Saúde da Família, } \\
\text { com no mínimo dois anos de } \\
\text { implantação, no Vale do Taquari } \\
\text { (RS). }\end{array}$ & $\begin{array}{l}\text { Foi confirmada a hipótese inicial de que o } \\
\text { índice de rotatividade era elevado, embora se } \\
\text { apresentasse bastante irregular de um ano } \\
\text { para outro. Da análise de conteúdo emergiram } \\
\text { nove categorias: estilo de gestão; as equipes } \\
\text { e o processo de trabalho; influência político- } \\
\text { partidária; regime de trabalho e remuneração; } \\
\text { condições de trabalho; conciliação entre a } \\
\text { vida profissional e a pessoal; oportunidades } \\
\text { de mercado; vínculo com a comunidade; } \\
\text { formação e perfil. Fatores extrínsecos e } \\
\text { intrínsecos influenciaram na rotatividade dos } \\
\text { profissionais. }\end{array}$ \\
\hline 7 & $\begin{array}{l}\text { Sancho et al. } \\
\qquad(2011)\end{array}$ & $\begin{array}{l}\text { Quantitativo } \\
\text { descritivo }\end{array}$ & $\begin{array}{l}\text { Avaliar o índice de rotatividade } \\
\text { de } 15.100 \text { trabalhadores da } \\
\text { Secretaria Municipal de Saúde de } \\
\text { Belo Horizonte (MG). }\end{array}$ & $\begin{array}{l}\text { O índice geral de rotatividade no período } \\
\text { estudado (julho de } 2008 \text { a junho de 2009) foi } \\
\text { de } 8,35 \% \text {. }\end{array}$ \\
\hline
\end{tabular}




\begin{tabular}{|c|c|c|c|c|}
\hline 8 & $\begin{array}{l}\text { Pierantoni et al. } \\
\qquad(2015)\end{array}$ & $\begin{array}{c}\text { Quantitativo } \\
\text { descritivo }\end{array}$ & $\begin{array}{l}\text { Calcular o índice de rotatividade } \\
\text { de } 250.926 \text { médicos que atuavam } \\
\text { em } 5.565 \text { municípios brasileiros. }\end{array}$ & $\begin{array}{l}\text { Constatou-se maior índice de rotatividade nas } \\
\text { regiões Sudeste e Sul, com médias superiores } \\
\text { à nacional }(36,7 \%) \text {. Evidenciou-se menor } \\
\text { média } \\
\text { na região Norte }(24,7 \%) .\end{array}$ \\
\hline \multicolumn{5}{|c|}{ Periódico Multidisciplinar } \\
\hline 9 & $\begin{array}{l}\text { Praça et al. } \\
\text { (2012) }\end{array}$ & $\begin{array}{c}\text { Quantitativo } \\
\text { descritivo }\end{array}$ & $\begin{array}{l}\text { Identificar os fatores que } \\
\text { determinam a rotatividade } \\
\text { dos servidores com cargo de } \\
\text { confiança do governo federal } \\
\text { brasileiro, buscando responder } \\
\text { à pergunta: a rotatividade } \\
\text { dos funcionários se deve a } \\
\text { escândalos de corrupção ou à } \\
\text { mudança do chefe do Executivo? }\end{array}$ & $\begin{array}{l}\text { Mudanças partidárias na direção dos } \\
\text { ministérios não necessariamente se } \\
\text { traduziram em mudanças na composição } \\
\text { dos cargos de confiança; funcionários de } \\
\text { confiança com funções de policymaking } \\
\text { em órgãos ministeriais foram mais afetados } \\
\text { pela mudança da chefia do que os demais; } \\
\text { funcionários de confiança da Presidência } \\
\text { da República tiveram, em média, a mesma } \\
\text { taxa de permanência que os funcionários de } \\
\text { outros órgãos; órgãos afetados por casos de } \\
\text { corrupção tiveram uma taxa de permanência } \\
\text { de cargos de confiança maior do que a dos } \\
\text { demais órgãos. }\end{array}$ \\
\hline
\end{tabular}

Fonte: Elaborado pelos autores.

\section{QUADRO 2 - Autores, ano, delineamento, objetivos e resultados principais das publicações empíricas sobre rotatividade publicadas em revistas de revistas de administração/gestão}

\begin{tabular}{|c|c|c|c|c|}
\hline $\mathbf{N}^{\circ}$ & Autor(es) (Ano) & Delineamento & Objetivo(s) & Resultados Principais \\
\hline 1 & $\begin{array}{l}\text { Ferreira e Freire } \\
\text { (2001) }\end{array}$ & $\begin{array}{l}\text { Qualitativo } \\
\text { descritivo }\end{array}$ & $\begin{array}{l}\text { Abordar a inter-relação da carga } \\
\text { de trabalho dos funcionários com } \\
\text { a ocorrência da alta rotatividade } \\
\text { de pessoal no contexto } \\
\text { sociotécnico de postos de } \\
\text { abastecimento de combustível. }\end{array}$ & $\begin{array}{l}\text { O esgotamento das estratégias de regulação } \\
\text { levou à rotatividade dos frentistas em } \\
\text { função das práticas organizacionais, do } \\
\text { custo humano físico (ficar em pé) e mental } \\
\text { (checagem dos pagamentos), dos baixos } \\
\text { salários, do custo monetário (por conta do } \\
\text { furo de caixa) e da distância entre o trabalho } \\
\text { prescrito e o real. }\end{array}$ \\
\hline 2 & $\begin{array}{c}\text { Ferreira e } \\
\text { Siqueira (2005) }\end{array}$ & $\begin{array}{l}\text { Quantitativo } \\
\text { inferencial }\end{array}$ & $\begin{array}{l}\text { Testar um modelo para intenção } \\
\text { de rotatividade, posicionando o } \\
\text { comprometimento organizacional } \\
\text { afetivo e a satisfação no trabalho } \\
\text { como seus antecedentes diretos } \\
\text { e percepção de justiça de } \\
\text { remuneração como antecedente } \\
\text { indireto. }\end{array}$ & $\begin{array}{c}\text { À medida que o indivíduo percebe justiça } \\
\text { na remuneração que recebe, está satisfeito } \\
\text { com o trabalho e comprometido afetivamente } \\
\text { com a empresa, tende a reduzir sua intenção } \\
\text { de deixar a empresa. O teste do modelo foi } \\
\text { confirmado. }\end{array}$ \\
\hline 3 & $\begin{array}{c}\text { Campos e Malik } \\
\text { (2008) }\end{array}$ & $\begin{array}{l}\text { Quantitativo } \\
\text { inferencial }\end{array}$ & $\begin{array}{l}\text { Verificar o índice de rotatividade } \\
\text { e de satisfação no trabalho } \\
\text { de médicos generalistas do } \\
\text { Programa Saúde da Família no } \\
\text { município de São Paulo (SP) } \\
\text { e correlacionar o índice de } \\
\text { rotatividade ao grau de satisfação } \\
\text { no trabalho. }\end{array}$ & $\begin{array}{l}\text { Foi encontrada uma correlação negativa } \\
\text { entre satisfação no trabalho e a rotatividade. } \\
\text { Fatores de satisfação no trabalho que } \\
\text { apresentaram maior correlação com } \\
\text { rotatividade foram: falta de capacitação, } \\
\text { distância das unidades e indisponibilidade } \\
\text { de materiais para realizar o trabalho. Quanto } \\
\text { à remuneração, a pesquisa indicou que o } \\
\text { salário atrai os médicos, mas não os mantém. }\end{array}$ \\
\hline 4 & $\begin{array}{l}\text { Margoto et al. } \\
\qquad(2010)\end{array}$ & $\begin{array}{l}\text { Qualitativo } \\
\text { descritivo }\end{array}$ & $\begin{array}{l}\text { Descrever e analisar o processo } \\
\text { de decisão que levou cinco } \\
\text { pessoas a se desligarem } \\
\text { espontaneamente das } \\
\text { organizações onde trabalhavam } \\
\text { e a buscarem novas formas } \\
\text { de atuação fora do domínio } \\
\text { burocrático. }\end{array}$ & $\begin{array}{l}\text { Valorização do lucro em detrimento das } \\
\text { pessoas, falta de reconhecimento pelo } \\
\text { esforço e dedicação, abuso de poder pelos } \\
\text { gerentes, incongruência entre o discurso } \\
\text { e a prática na organização, sobrecarga } \\
\text { de trabalho, falta de tempo para cuidar } \\
\text { da família, choque entre valores pessoais } \\
\text { e organizacionais e perda do sentido do } \\
\text { trabalho foram alguns dos motivos apontados } \\
\text { pelos entrevistados que optaram por buscar } \\
\text { novas formas de ocupação e de vida. }\end{array}$ \\
\hline
\end{tabular}




\begin{tabular}{|c|c|c|c|c|}
\hline 5 & $\begin{array}{c}\text { Cavazotte et al. } \\
(2010)\end{array}$ & $\begin{array}{l}\text { Quantitativo } \\
\text { inferencial }\end{array}$ & $\begin{array}{l}\text { Analisar se, para } 172 \text { mulheres } \\
\text { que trabalhavam no Rio de } \\
\text { Janeiro, a discriminação de } \\
\text { gênero criaria dificuldades } \\
\text { adicionais sobre sua intenção de } \\
\text { deixar a empresa. }\end{array}$ & $\begin{array}{c}\text { A percepção de desigualdade teve impacto } \\
\text { negativo sobre as atitudes das mulheres em } \\
\text { relação ao seu emprego e às organizações } \\
\text { onde trabalhavam; o sentido do trabalho } \\
\text { apresentou efeitos moderadores; por meio } \\
\text { de seus efeitos sobre as atitudes das } \\
\text { mulheres, a percepção de desigualdade } \\
\text { afetou significativamente a intenção de deixar } \\
\text { a empresa. }\end{array}$ \\
\hline 6 & Vieira (2011) & $\begin{array}{l}\text { Quantitativo } \\
\text { descritivo }\end{array}$ & $\begin{array}{l}\text { Verificar a variação do índice de } \\
\text { rotatividade de pessoal de uma } \\
\text { universidade pública estadual, de } \\
1999 \text { a } 2009 \text {, e compará-lo com a } \\
\text { média brasileira. }\end{array}$ & $\begin{array}{c}\text { As categorias docente e técnico- } \\
\text { administrativo tiveram índices diferentes, } \\
\text { sendo a rotatividade maior na categoria } \\
\text { docente. Os docentes saíram mais no final da } \\
\text { carreira e os técnicos no início. }\end{array}$ \\
\hline 7 & $\begin{array}{l}\text { Lopes et al. } \\
\text { (2011) }\end{array}$ & $\begin{array}{l}\text { Quantitativo } \\
\text { inferencial }\end{array}$ & $\begin{array}{c}\text { Entender a relação entre } \\
\text { as dimensões de justiça } \\
\text { (informacional, distributiva, } \\
\text { procedimental e interpessoal) } \\
\text { e a motivação, a lealdade e a } \\
\text { intenção de turnover de equipes } \\
\text { de vendas. }\end{array}$ & $\begin{array}{c}\text { A relação entre justiça interpessoal e intenção } \\
\text { de turnover foi maior que a relação entre } \\
\text { justiça distributiva e intenção de turnover. } \\
\text { Os resultados indicaram a importância } \\
\text { da manutenção de um bom ambiente de } \\
\text { trabalho, no qual os gestores devem reforçar } \\
\text { o aspecto de compromisso com sua equipe } \\
\text { de vendas. }\end{array}$ \\
\hline 8 & $\begin{array}{l}\text { Rosa e Ibdaiwi } \\
\quad(2012)\end{array}$ & $\begin{array}{l}\text { Quanti-quali } \\
\text { descritivo }\end{array}$ & $\begin{array}{c}\text { Analisar o clima organizacional, } \\
\text { focando na motivação e na } \\
\text { rotatividade de } 57 \text { trabalhadores } \\
\text { de uma grande empresa de fast } \\
\text { food da cidade de Santa Maria } \\
\text { (RS). }\end{array}$ & $\begin{array}{c}\text { O nível de rotatividade era elevado: } 57,9 \% \\
\text { ainda não tinham completado três meses } \\
\text { de empresa ao se desligarem. As causas do } \\
\text { alto percentual talvez decorreram da pouca } \\
\text { idade, de que } 32 \% \text { sentiam-se desvalorizados } \\
\text { e não reconhecidos pelo seu trabalho, e ao } \\
\text { ambiente emocional e psicológico insalubre } \\
\text { da organização, apontado por } 32,1 \% \text { dos } \\
\text { respondentes. }\end{array}$ \\
\hline 9 & $\begin{array}{l}\text { Oliveira et al. } \\
\qquad(2013)\end{array}$ & $\begin{array}{l}\text { Quantitativo } \\
\text { inferencial }\end{array}$ & $\begin{array}{l}\text { Avaliar o impacto de certas } \\
\text { práticas de RH de empresas } \\
\text { sobre o conflito trabalho-família } \\
\text { e o conflito família-trabalho. } \\
\text { Foram testados os efeitos desses } \\
\text { conflitos sobre a satisfação no } \\
\text { trabalho, a intenção de deixar } \\
\text { a empresa, o estresse e o } \\
\text { absenteísmo. }\end{array}$ & $\begin{array}{c}\text { Funcionários mais velhos, com dez ou } \\
\text { mais anos na organização e aqueles } \\
\text { que trabalhavam em empresas públicas } \\
\text { apresentaram níveis menores de intenção de } \\
\text { deixar a empresa. Evidências indicaram que } \\
\text { o conflito trabalho-família reduziu a satisfação } \\
\text { no trabalho e aumentou a intenção do } \\
\text { profissional de deixar a empresa. }\end{array}$ \\
\hline 10 & $\begin{array}{c}\text { Maciel e } \\
\text { Camargo (2013) }\end{array}$ & $\begin{array}{l}\text { Quantitativo } \\
\text { inferencial }\end{array}$ & $\begin{array}{c}\text { Verificar a influência da } \\
\text { sobrequalificação percebida } \\
\text { no trabalho sobre satisfação, } \\
\text { intenção de saída e cooperação } \\
\text { do indivíduo na organização. }\end{array}$ & $\begin{array}{l}\text { A intenção de saída foi influenciada tanto } \\
\text { pela falta de oportunidades de aprendizagem } \\
\text { e desafios (contracrescimento), quanto } \\
\text { pela distância entre o que o indivíduo fazia } \\
\text { no trabalho e aquilo que poderia fazer em } \\
\text { função de suas qualificações (incongruência). } \\
\text { Quanto menor a satisfação no trabalho, maior } \\
\text { a intenção de saída e, por consequência, a } \\
\text { rotatividade. A hipótese de que havia relação } \\
\text { entre intenção de saída e cooperação não foi } \\
\text { confirmada|: a intenção de saída não alterou } \\
\text { o comportamento cooperativo. }\end{array}$ \\
\hline 11 & $\begin{array}{l}\text { Vasconcellos e } \\
\text { Neiva (2014) }\end{array}$ & $\begin{array}{l}\text { Quanti-quali } \\
\text { inferencial }\end{array}$ & $\begin{array}{l}\text { Investigar como os indivíduos } \\
\text { avaliavam seu futuro profissional } \\
\text { na organização atual, explorando } \\
\text { a relação dessa variável com } \\
\text { perfil demográfico, intenção de } \\
\text { desligamento e bem-estar no } \\
\text { trabalho. }\end{array}$ & $\begin{array}{l}\text { A avaliação de futuro profissional se associou } \\
\text { fortemente a intenções de desligamento: } \\
88 \% \text { dos indivíduos que relataram futuro } \\
\text { profissional favorável não tinham intenção de } \\
\text { se desligar nos próximos dois anos. }\end{array}$ \\
\hline
\end{tabular}




\begin{tabular}{|c|c|c|c|c|}
\hline 12 & $\begin{array}{c}\text { Carrara et al. } \\
\quad(2014)\end{array}$ & $\begin{array}{l}\text { Quanti-quali } \\
\text { inferencial }\end{array}$ & $\begin{array}{c}\text { Identificar se fatores } \\
\text { organizacionais: ambiente } \\
\text { organizacional, configuração } \\
\text { do trabalho, condições de } \\
\text { trabalho, gestão do líder, } \\
\text { carreira, remuneração total, } \\
\text { capacitação e desenvolvimento } \\
\text { podem influenciar profissionais } \\
\text { considerados talentos, } \\
\text { pertencentes às gerações } \\
\text { baby boomers, X e Y, quanto } \\
\text { à permanência ou intenção de } \\
\text { deixar a organização. }\end{array}$ & $\begin{array}{l}\text { Na dimensão saída, destacaram-se os } \\
\text { fatores remuneração e benefícios, seguido } \\
\text { do ambiente organizacional. Os profissionais } \\
\text { valorizavam principalmente o respeito, } \\
\text { quanto o trabalho permite conciliar a vida } \\
\text { profissional com a pessoal e a existência de } \\
\text { oportunidades de crescimento profissional } \\
\text { na decisão tanto de permanência quanto } \\
\text { de saída. O tempo gasto no deslocamento } \\
\text { foi um aspecto influente na saída daqueles } \\
\text { que residiam em cidades distantes do } \\
\text { local de trabalho. Resultados indicaram } \\
\text { não existir diferenças significativas entre } \\
\text { as três gerações quanto a sair ou ficar na } \\
\text { organização. }\end{array}$ \\
\hline 13 & $\begin{array}{c}\text { Oliveira e } \\
\text { Honório (2014) }\end{array}$ & $\begin{array}{l}\text { Qualitativo } \\
\text { descritivo }\end{array}$ & $\begin{array}{l}\text { Analisar fatores de atração } \\
\text { e perda de jovens que } \\
\text { voluntariamente optaram por } \\
\text { deixar uma grande empresa do } \\
\text { setor jornalístico. }\end{array}$ & $\begin{array}{c}\text { Traços da cultura organizacional } \\
\text { apresentaram contraste com aspectos } \\
\text { valorizados pelos participantes, indicando } \\
\text { incongruência de valores, que poderia levar } \\
\text { a organização a perder jovens talentos. Com } \\
\text { relação às motivações pessoais para deixar a } \\
\text { empresa, foram identificados três grupos de } \\
\text { jovens: idealistas, carreiristas e imediatistas, } \\
\text { orientados por anseios e perspectivas } \\
\text { profissionais distintos. }\end{array}$ \\
\hline 14 & $\begin{array}{l}\text { Silva et al. } \\
\text { (2014) }\end{array}$ & $\begin{array}{l}\text { Quantitativo } \\
\text { inferencial }\end{array}$ & $\begin{array}{l}\text { Analisar o impacto das variáveis } \\
\text { antecedentes: percepção } \\
\text { de suporte organizacional, } \\
\text { comprometimento organizacional } \\
\text { afetivo, idade, gênero, tempo } \\
\text { de trabalho e chefia como } \\
\text { antecedentes diretos da intenção } \\
\text { de rotatividade. }\end{array}$ & $\begin{array}{l}\text { Apenas dois construtos tiveram impacto } \\
\text { negativo significativo sobre a intenção de } \\
\text { rotatividade, sendo que o comprometimento } \\
\text { afetivo teve maior impacto que o suporte } \\
\text { organizacional. }\end{array}$ \\
\hline 15 & $\begin{array}{c}\text { Ferreira e } \\
\text { Almeida (2015) }\end{array}$ & $\begin{array}{l}\text { Quantitativo } \\
\text { inferencial }\end{array}$ & $\begin{array}{l}\text { Verificar se ações de } \\
\text { reconhecimento (quantidade de } \\
\text { promoções ou aumentos salariais } \\
\text { aplicados) e investimento em } \\
\text { horas-treinamento profissional } \\
\text { reduzem a rotatividade de } \\
\text { funcionários. }\end{array}$ & $\begin{array}{l}\text { As hipóteses "quanto maior a frequência de } \\
\text { aplicação de promoções e aumentos salariais, } \\
\text { menores são as taxas de rotatividade da } \\
\text { filial" e "quanto maior a quantidade de } \\
\text { horas treinamento por funcionário aplicada, } \\
\text { menores são as taxas de rotatividade da filial" } \\
\text { não foram confirmadas. }\end{array}$ \\
\hline 16 & $\begin{array}{l}\text { Agapito et al. } \\
\qquad(2015)\end{array}$ & $\begin{array}{l}\text { Quantitativo } \\
\text { inferencial }\end{array}$ & $\begin{array}{c}\text { Analisar as relações entre } \\
\text { percepções de sucesso na } \\
\text { carreira, bem-estar no trabalho } \\
\text { e intenção de rotatividade em } \\
\text { trabalhadores do Sudeste do } \\
\text { Brasil. }\end{array}$ & $\begin{array}{l}\text { As dimensões de bem-estar no trabalho } \\
\text { exerceram forte e significativo impacto sobre } \\
\text { a intenção de rotatividade dos profissionais, } \\
\text { enquanto a percepção de sucesso na carreira } \\
\text { contribuiu com valores baixos nesse impacto, } \\
\text { devido ao formato do modelo hipotético. }\end{array}$ \\
\hline
\end{tabular}

Fonte: Elaborado pelos autores.

QUADRO 3 - Síntese dos motivos/antecedentes identificados nos estudos sobre rotatividade

\begin{tabular}{|l|l|}
\hline \multicolumn{1}{|c|}{ Motivos/Antecedentes } & \multicolumn{1}{c|}{ Quantidade (Estudos) } \\
\hline Remuneração inadequada & $\begin{array}{l}\text { 4 (FERREIRA; FREIRE, 2001; FERREIRA; SIQUEIRA, 2005; MEDEIROS et } \\
\text { al., 2010; CARRARA et al., 2014) }\end{array}$ \\
\hline $\begin{array}{l}\text { Baixa percepção de suporte organizacional / } \\
\text { Más condições de trabalho }\end{array}$ & $\begin{array}{l}\text { 4 (CAMPOS; MALIK, 2008; FERREIRA; FREIRE, 2001; MEDEIROS et al., } \\
\text { 2010; SILVA et al., 2014) }\end{array}$ \\
\hline $\begin{array}{l}\text { Oportunidades de crescimento na carreira } \\
\text { dentro da organização }\end{array}$ & $\begin{array}{l}\text { 4 (AGAPITO et al., 2015; CARRARA et al., 2014; FERREIRA; ALMEIDA, 2015; } \\
\text { OLIVEIRA; HONORIO, 2014) }\end{array}$ \\
\hline Percepção de justiça / Justiça interpessoal & 3 (FERREIRA; SIQUEIRA, 2005; MARGOTO et al., 2010; LOPES et al., 2011) \\
\hline
\end{tabular}




\begin{tabular}{|c|c|}
\hline Práticas e reconhecimento / valorização & 3 (MARGOTO et al., 2010; ROSA; IBDAIWI, 2012; FERREIRA; ALMEIDA, 2015) \\
\hline Capacitação e orientação & 2 (CAMPOS; MALIK, 2008; FERREIRA; ALMEIDA, 2015) \\
\hline Estilo de gestão autoritário & 2 (MARGOTO et al., 2010; MEDEIROS et al., 2010) \\
\hline Reorganização do sistema de saúde & 1 (IWAMOTO; ANSELMI, 2006) \\
\hline Empresa privada & 1 (OLIVEIRA et al., 2013) \\
\hline Avaliação de futuro profissional & 1 (VASCONCELOS; NEIVA, 2014) \\
\hline Equilíbrio trabalho-família & $\begin{array}{l}5 \text { (BEZERRA, 1997; CARRARA et al., 2014; MARGOTO et al., 2010; } \\
\text { MEDEIROS et al., 2010; OLIVEIRA et al., 2013) }\end{array}$ \\
\hline Influência político-partidária & 2 (MEDEIROS et al., 2010; PRAÇA et al., 2012) \\
\hline $\begin{array}{l}\text { Recrutamento por outra empresa/ Novas } \\
\text { oportunidades no mercado }\end{array}$ & 2 (BEZERRA, 1997; MEDEIROS et al., 2010) \\
\hline $\begin{array}{l}\text { Distância das unidades de saúde / Tempo } \\
\text { gasto no deslocamento ao trabalho }\end{array}$ & 2 (CAMPOS; MALIK, 2008; CARRARA et al., 2014) \\
\hline Casos de corrupção & 1 (PRAÇA et al., 2012) \\
\hline Forte vínculo com a comunidade & 1 (MEDEIROS et al., 2010) \\
\hline Percepção de discriminação de gênero & 1 (CAVAZOTTE et al., 2010) \\
\hline $\begin{array}{l}\text { Formação fragmentada dos profissionais de } \\
\text { saúde }\end{array}$ & 1 (MEDEIROS et al., 2010) \\
\hline $\begin{array}{l}\text { Satisfação no trabalho / } \\
\text { Bem-estar no trabalho }\end{array}$ & $\begin{array}{l}5 \text { (AGAPITO et al., 2015; CAMPOS; MALIK, 2008; CAVAZOTTE et al., 2010; } \\
\text { FERREIRA; SIQUEIRA, 2005; MACIEL; CAMARGO, 2013) }\end{array}$ \\
\hline Perda do sentido do trabalho & 1 (MARGOTO et al., 2010) \\
\hline Comprometimento organizacional afetivo & 2 (FERREIRA; SIQUEIRA, 2005; SILVA et al., 2014) \\
\hline $\begin{array}{l}\text { Choque entre valores pessoais e } \\
\text { organizacionais }\end{array}$ & 2 (OLIVEIRA; HONÓRIO, 2014; MARGOTO et al., 2010) \\
\hline Identificação com a organização & 2 (BEZERRA, 1997; CAVAZOTTE et al., 2010) \\
\hline Sobrecarga de trabalho & 2 (MARGOTO et al., 2010; ROSA; IBDAIWI, 2012) \\
\hline $\begin{array}{l}\text { Custo humano do trabalho ou elevada carga } \\
\text { emocional, física, cognitiva }\end{array}$ & 2 (FERREIRA; FREIRE, 2001; ROSA; IBDAIWI, 2012) \\
\hline Vínculo precário de trabalho & 1 (MEDEIROS et al., 2010) \\
\hline Falta de desafios no trabalho & 1 (OLIVEIRA; HONÓRIO, 2014) \\
\hline Ocupar cargo de chefia & 1 (SILVA et al., 2014) \\
\hline Idade & $\begin{array}{l}4 \text { (OLIVEIRA et al., 2013; CARRARA et al., 2014; ROSA; IBDAIWI, 2012; } \\
\text { SILVA et al., 2014) }\end{array}$ \\
\hline Tempo na organização & 2 (OLIVEIRA et al., 2013; SILVA et al., 2014) \\
\hline Gênero & 1 (SILVA et al., 2014) \\
\hline Sobrequalificação percebida & 1 (MACIEL; CAMARGO, 2013) \\
\hline $\begin{array}{l}\text { Dificuldade de trabalhar em equipe (excesso } \\
\text { de competitividade) }\end{array}$ & 1 (MEDEIROS et al., 2010) \\
\hline
\end{tabular}

Fonte: Elaborado pelos autores.

O Quadro 3 apresenta uma síntese dos motivos/antecedentes que os estudos identificaram como associados a/ou fontes da rotatividade, bem como quantos e quais estudos apontaram tais razões. Adotou-se o termo motivos para fazer referência aos estudos descritivos, mas que discutiram as possíveis razões da rotatividade, tanto quan- titativos quanto qualitativos. $O$ termo antecedentes refere-se aos estudos que realizaram análises inferenciais.

Os artigos foram classificados em mais de uma categoria, como mostra o Quadro 3. Dos 68 motivos/antecedentes analisados, a maioria ( 25 ou $36,8 \%$ ) se referiu a políticas e práticas organizacionais (e.g. re- 
muneração, práticas de valorização de pessoal). A segunda categoria mais frequente esteve relacionada a fatores sociais (e.g. tempo de deslocamento para o trabalho, casos de corrupção) e representou 15 motivos/antecedentes (22, I\%).

As atitudes ou afetos relacionados ao trabalho representaram seis motivos e as atitudes ou afetos relacionados às organizações também englobaram seis. Dessa forma, 12 motivos (17,6\%) dos 68 identificados eram associados a fatores atitudinais e afetivos. As características pessoais (e.g. idade, tempo de serviço) envolveram nove modalidades de motivos/antecedentes (I $3,2 \%)$ e, por fim, fatores ocupacionais (e.g. sobrecarga de trabalho, custo humano, autonomia) abarcaram sete (10,3\%).

Entre os 25 estudos analisados, cinco deles (ANSELMI et al., I 997; NOMURA; GAIDZINSKI, 2005; SANCHO et al., 20I I;VIEIRA, 20I I; PIERANTONI et al., 20I5) não foram citados no Quadro 3 porque tinham como objetivo identificar os níveis de rotatividade por período, setor ou organização hospitalar (todos da saúde/enfermagem); isto é, eles não analisaram e/ou discutiram os motivos que poderiam ter ocasionado tais taxas. $O$ artigo de Holanda e Cunha (2005) também não foi incluído no Quadro 3: os autores investigaram o valor monetário médio dos profissionais de recursos humanos $(\mathrm{RH})$ para admissão, treinamento e desligamento de enfermeiros, sem menção a antecedentes/motivos da rotatividade.

Por fim, notou-se que poucos estudos avaliaram os consequentes da rotatividade. À guisa de exemplo, as altas taxas de rotatividade podem levar ao aumento dos custos, a quedas de produtividade e a uma maior dificuldade de consolidação do Sistema Único de Saúde (SUS) afirmaram Ansel- mi et al. (1997), que não chegaram a testar tais hipóteses.

\section{DISCUSSÃO}

A compreensão dos fatores que influenciam a rotatividade nas organizações deve ser de interesse da alta administração, já que a perda de bons empregados afeta a produtividade e o desempenho financeiro destas e pode prejudicar as estratégias em busca de competitividade (HOM et al., 2017). Nessa perspectiva, a sistematização da produção científica empírica nacional sobre rotatividade é relevante por propiciar uma visão do estado da arte e prover subsídios à realização de pesquisas futuras, dada a constatação de escassez de publicações.

Cotejar a tradição internacional de pesquisa com a nacional é relevante no sentido de observar a situação brasileira em âmbito global, já que devido às diferenças sociohistóricas, políticas, econômicas e culturais, os estudos sobre Comportamento Organizacional no Brasil não caminham lado a lado como os norte-americanos e europeus, tal como descrito por Roe (2018). Com relação ao tempo a que se dedicam ao estudo da rotatividade, vimos que há concentração de registros de publicações internacionais específicas sobre o tema desde meados do século passado (BRAYFIELD; CROCKETT, 1955), enquanto que, no Brasil, notou-se um aumento relevante a partir de 2006, segundo resultados do presente estudo. Essa distância - de meados do século $X X$ início do século $X X I$ - sinaliza aos pesquisadores brasileiros a necessidade que ainda temos de caminhar.

Merece destaque que os modelos teóricos complexos, adotados por investigações estrangeiras, permitem compreender os antecedentes com maior clareza já que se 
preocuparam em buscar as fontes dos antecedentes, mediadores e moderadores da rotatividade (HOM et al., 2017). Ou seja, a tradição internacional apresenta um claro predomínio de pesquisas de natureza quantitativa com análise inferencial de dados, que variam desde a análise de variâncias e fatoriais a regressões multinível e equações estruturais (ONGORI, 2007; STEEL; LOUNSBURY, 2009; HOM et al., 2017). Em contraposição, a produção brasileira, identificada nesse estudo, indica o predomínio de estudos descritivos quantitativos e qualitativos, sem testes de hipóteses e investigação de associações entre variáveis. E a maioria dos estudos inferenciais sobre a realidade brasileira verificou associações diretas entre variáveis, sem testar moderações e mediações.

Há evidências de construtos psicológicos como principais preditores da rotatividade, tais como atitudes, satisfação e comprometimento (STEEL; LOUNSBURY, 2009). Os resultados dos estudos nacionais de Campos e Malik (2008), Ferreira e Siqueira (2005) e Maciel e Camargo (2013), sobre a associação negativa consistente entre satisfação no trabalho e intenção de rotatividade, foram ao encontro dos verificados por Kevin et al. (2004), Ongori (2007) e Steel e Lounsbury (2009). Os aspectos atitudinais e/ou afetivos, pessoais e ocupacionais, frequentes na literatura internacional (ONGORI, 2007; STEEL; LOUNSBURY, 2009), apareceram de forma secundária nos dados dos estudos aqui revisados. Pesquisas empíricas sobre os fatores pessoais poderiam ajudar gestores e analistas de gestão de pessoas a realizar seus processos de recrutamento e seleção de forma mais eficaz.

De maneira geral, é importante ressaltar que grande parte dos fatores associa- dos à rotatividade na amostra de estudos empíricos do presente estudo diz respeito a políticas e práticas organizacionais e do trabalho, seguidas por fatores sociais, como descrito no Quadro 3. Além disso, os modelos conceituais internacionais estão focados no processo e nos fatores que afetam a tomada de decisão para sair/ficar na organização (HOM et al., 2017), enquanto que os estudos brasileiros ainda permitem poucas conclusões sobre esse processo.

Nota-se que a rotatividade entre profissionais de enfermagem e medicina é elevada e que a falta de suporte organizacional (e.g. equipamentos, instrumentos e medicamentos para cuidado dos pacientes) representa um dos principais motivos (CAMPOS; MALIK, 2008; MEDEIROS et al., 20 I0) para a intenção e para o comportamento de saída. Além disso, observou-se que a rotatividade em hospitais privados costuma ser maior que em hospitais públicos. Os estudos do campo da enfermagem carecem de maior desenvolvimento teórico e metodológico e as instituições hospitalares seriam beneficiadas se os pesquisadores se preocupassem em identificar também os antecedentes e/ ou mediadores da rotatividade, além de medir sua ocorrência e frequência.

Esta revisão da produção científica nacional revelou que as pesquisas brasileiras sobre desligamento e intenção de saída encontram-se defasadas não apenas em relação às publicações internacionais, que comemoram um século de existência, mas especialmente no que se refere aos métodos adotados. Interessante notar que foram identificados artigos nos periódicos de psicologia sobre o tema no período do levantamento. Porém, boa parte dos construtos investigados, associados ao fenômeno, eram de natureza psicológica. 
A reduzida produção nacional somada à dispersão de autores e instituições de origem sugere uma possível fragilidade de parcerias entre pesquisadores das universidades brasileiras para investigação do tema, bem como a existência de poucas linhas de pesquisa sobre $o$ assunto. Para ratificar essa análise, indica-se que estudos futuros sobre redes de colaboração sejam realizados. É importante a construção de redes de pesquisadores para criar robustez teórica e metodológica sobre determinado construto, como defende Schein (20I5). Seria interessante ainda confirmar se os processos investigados em nível internacional podem ser generalizados para o Brasil ou se há aqui processos autóctones decorrentes deste contexto específico.

Outra perspectiva de análise que também não foi encontrada na literatura nacional seria avaliar se os antecedentes das intenções dos trabalhadores de deixar a organização ao longo da carreira são iguais ou diferentes das intenções de se aposentar. Por exemplo, em um estudo holandês, características pessoais como renda, idade e saúde explicaram melhor as intenções dos trabalhadores de se aposentar, enquanto que as características do trabalho foram melhores preditores de rotatividade (MÜNDERLEIN et al., 2013).

Ainda há poucas pesquisas nacionais que atravessam as dimensões micro e macro do comportamento dentro das organizações. Por exemplo, pouco se sabe sobre os efeitos de uma gestão centralizada versus uma descentralizada diante da rotatividade dos trabalhadores.Assim, sugere-se a condução de pesquisas que façam esse recorte transversal do macro ao micro, especialmente porque é sabido que distância de poder é variável sociocultural que diferencia o Bra- sil de muitos países onde são coletados dados sobre esses tipos de gestão (BORGES -ANDRADE; PAGOTTO, 2010).

Um grande desafio que deve ser incorporado às agendas de pesquisa em rotatividade refere-se à preocupação em atender não apenas às lacunas teóricas e metodológicas, mas também às práticas. Há poucas orientações sobre como os gestores e trabalhadores podem intervir no ambiente organizacional com base nos resultados dessas investigações. A Psicologia Organizacional e do Trabalho (POT) compreende dois tipos de ciência: a ciência explanatória, que objetiva compreender a realidade; e a tecnológica, que visa transformá-la (ROE, 2018).Ambas são importantes, mas há uma tendência de se focar na primeira para, em seguida, produzir a segunda.

Novos caminhos da pesquisa científica nacional sobre esse tema precisam ser triIhados, quantitativa e qualitativamente, isto é, com uma fundamentação teórica sólida, ancorada em modelos e pesquisas já desenvolvidos, com amostras diversificadas e análises de dados que permitam inferir relações entre as variáveis. Espera-se ainda que pesquisadores da psicologia investiguem e publiquem mais estudos sobre o tema.

Esta revisão também apresenta limitações. Poder-se-ia ampliar o escopo temporal e buscar todos os estudos sobre rotatividade já publicados no Brasil, com inclusão de outras bases de dados. Revisões vindouras sobre o tema também podem incorporar resultados de dissertações de mestrado, teses de doutorado, capítulos de livro e outros tipos de publicações acadêmicas e profissionais.

De todo modo, a presente revisão da literatura forneceu um panorama do campo de pesquisa sobre rotatividade no Brasil 
em vinte anos. É preciso que a discussão de natureza conceitual e metodológica encoraje pesquisadores de vários campos do conhecimento a se interessar em ampliar e melhorar a qualidade da nossa produção científica. Em prol de um Brasil mais produtivo e de trabalhadores mais satisfeitos, é urgente que gestores sejam sensibilizados e instrumentalizados sobre como manter índices mais baixos de rotatividade. 


\section{REFERÊNCIAS}

AGAPITO, P. R.; POLIZZI, A. P. F.; SIQUEIRA, M. M. M. Bem-estar no trabalho e percepção de sucesso na carreira como antecedentes de intenção de rotatividade. Revista de Administração Mackenzie, v. I6, n. 6, Edição Especial, p. 7|-93, 2015.

ANSELMI, M. L.; ANGERAMI, E. L. S.; GOMES, E. L. R. Rotatividade dos trabalhadores de enfermagem nos hospitais do Município de Ribeirão Preto. Revista Panamericana de Salud Pública, v. 2, n. I, p. 44-50, 1997.

BEZERRA, A. L. Q. O significado da rotatividade de pessoal numa instituição de saúde privada. Revista Brasileira de Enfermagem, v. 50, n. I, p. I07-I 20, 1997.

BORGES-ANDRADE, J. A.; PAGOTTO, C.P.O estado da arte da pesquisa brasileira em Psicologia do Trabalho e Organizacional. Psicologia: Teoria e Pesquisa, v. 26, número especial, p. 37-50, 2010.

BRAYFIELD, A. H.; CROCKETT,W. H. Employee attitudes and employee performance. Psychological Bulletin, v. 52, n. 05, p. 396-424, 1955.

CAMPOS, C. V. A.; MALIK, A. M. Satisfação no trabalho e rotatividade dos médicos do Programa de Saúde da Família. Revista de Administração Pública, v. 42, n. 2, p. 347-368, 2008.

CARRARA, T. M. P.; NUNES, S. C.; SARSUR, A. M. Fatores de retenção, permanência e desligamento de talentos e de performers. Revista de Administração, Contabilidade e Economia, v. I3, n. 3, p. I | |9-I|48, 20|4. Disponível em: <http://editora.unoesc.edu. br/index.php/race>

CAVAZOTTE, F. S. C. N.; OLIVEIRA, L. B.; MIRANDA, L. C. Desigualda- de de gênero no trabalho: reflexos nas atitudes das mulheres e em sua intenção de deixar a empresa. Revista de Administração da USP, v. 45, n. I, p. 70-83, 2010. DIEESE - DEPARTAMENTO INTERSINDICAL DE ESTATÍSTICA E ESTUDOS SOCIOECONÔMICOS. Rotatividade e políticas públicas para o mercado de trabalho, São Paulo, 20|4. Disponível em: <http://goo.gl//Z3×0b>

FERREIRA, L. C. M.; ALMEIDA, C. B. A. Rotatividade de funcionários e desempenho organizacional: um estudo no comércio brasileiro. Brazilian Administration Review, v. I2, n. 4, p. 28-6I, 2015.

FERREIRA, M. C.; FREIRE, O. N. Carga de trabalho e rotatividade na função de frentista. Revista de Administração Contemporânea, v. 5, n. 2, p. I75-200, 200 I.

FERREIRA, M. L. C. B.; SIQUEIRA, M. M. M. Antecedentes de intenção de rotatividade: estudo de um modelo psicossocial. Organizações em Contexto, v. I, n. 2, p. 47-67, 2005.

HARKINS, P. J. Why employees stay or go. Workforce, v. 77, n. 10, p. 74-78, 1998.

HEAVEY, A. L.; HOLWERDA, J. A.; HAUSKNECHT, J. P. Causes and consequences of collective turnover: A meta-analytic review. Journal of Applied Psychology, v. 98, n. 3, p. 4I2-453, 2013.

HERZBERG, F. et al. Job attitudes: review of research and opinion. Industrial and Labor Relations Review, Psychological Service of Pittsburgh, Pittsburgh, 1957.

HOLANDA, F. L.; CUNHA, I. C. K. O. Tempo de permanência de enfermeiros em um hospital-escola e valores monetários despendidos nos processos de admissão, des- ligamento e provimento de novo profissional. Revista Latino-americana de Enfermagem, v. I3, n. 5, p. 642-647, 2005.

HOM, P.W. et al. One hundred years of employee turnover theory and research. Journal of Applied Psychology, v. I02, n. 3, p. 530545, 2017.

IWAMOTO, H. H.; ANSELMI, M. L. Rotatividade dos trabalhadores de enfermagem nos hospitais do município de Uberaba, Minas Gerais. Revista Gaúcha de Enfermagem, v. 27, n. 3, p. 443-453, 2006.

KEVIN, M. M.;JOAN, L. C.;ADRIAN,J. W. Organizational change and employee turnover. Personnel Review, v. 33, n. 2, p. I6I-I66, 2004.

LEE, T.W., \& MITCHELL, T. R. An alternative approach: The unfolding model of voluntary employee turnover. Academy of Management Review, v. 19, n. I, p. 5 I-89, 1994.

LOPES, E. L.; MORETTI, S. L. A.; ALEJANDRO,T. B.Avaliação de justiça e intenção de turnover em equipes de vendas: teste de um modelo teórico. Revista de Administração de Empresas, v. 5I, n. 6, p. 553-567, 20 I I.

MACIEL, C. O.; CAMARGO, C. Sobrequalificação no trabalho e sua influência sobre atitudes e comportamentos. Revista de Administração Contemporânea, v. I7, n. 2, p. 218-238, 2013.

MARGOTO,J. B.; BEHR, R. R.; PAULA, A. P. P. Eu me demito! Evidências da racionalidade substantiva nas decisões de desligamento em organizações. Organização \& Sociedade, v. 17, n. 52, p. II5-135, 2010.

MEDEIROS, C. R. G. et al. A rotatividade de enfermeiros e médicos: 
um impasse na implementação da Estratégia de Saúde da Família. Ciência \& Saúde Coletiva, v. I5, n. supl. I, p. I52I-I53I, 2010.

MÜNDERLEIN, M.;YBEMA, J. F.; KOSTER, F. Happily ever after? Explaining turnover and retirement intentions of older workers in The Netherlands. Career Development International, v. 18, n. 6, p. 548-568, 2013.

NERY, P. F. O que é rotatividade (e por que é um problema)? Brasil, Economia e Governo, 15 abr. 20I5. Disponível em: <http:// www.brasil-economia-governo. org.br/2015/04/I5/o-que-e-rotatividade-e-por-que-e-um-proble$\mathrm{ma} />$

NOMURA, F. H.; GAIDZINSKI, R. R. Rotatividade da equipe de enfermagem: estudo em hospital-escola. Revista Latino-americana de Enfermagem, v. 13, n. 5, p. 648-653, 2005.

OLIVEIRA, L. B.; CAVAZOTTE, F. S. C. N.; PACIELLO, R. R. Antecedentes e consequências dos conflitos entre trabalho e família. Revista de Administração Contemporânea, v. 17, n. 4, p. 418-437, 2013. Disponível em: <http:// dx.doi.org//0.1590/S I 4 I 5 655520|3000400003>

OLIVEIRA, L. B.; HONÓRIO, S. R. F. S. Atração e desligamento voluntário de jovens empregados: um estudo de caso no setor jornalístico. Revista de Administração da USP, v. 49, n. 4, p. 7|4-730, 2014.

ONGORI, H. A review of the literature on employee turnover. African Journal of Business Management, v. I, n. 2, p. 49-54, 2007.

PIERANTONI, C. R. et al. Rotatividade da força de trabalho médica no Brasil. Saúde em Debate, v. 39, n. 106, p. 637-647, 2015.

POCHMANN, M. O trabalho na cri- se econômica no Brasil: primeiros sinais. Estudos Avançados, São Paulo, v. 23, n. 66, p. 4l-52, 2009.

PRAÇA, S.; FREITAS, A.; HOEPERS, B. A rotatividade dos servidores de confiança no Governo Federal Brasileiro, 2010/201 I. Novos Estudos, v. 94, p. 91-107, 2012.

PRICE, J. L. The study of turnover. lowa: State University Press, 1977. ROBBINS, S. P.; JUDGE, T. A.; SOBRAL, F. Comportamento organizacional. Teoria e prática no contexto brasileiro. $14^{\mathrm{a}}$ ed. São Paulo: Pearson Prentice Hall, 2010.

ROE, R. A. Industrial, work and organizational psychology in Europe. In: ONES, D. S. et al. (Orgs.). The SAGE handbook of industrial, work \& organizational psychology, v. 3. London: SAGE, 2018, p. 46-75.

ROSA, M. S.; IBDAIWI, T. K. Fatores responsáveis pelo turnover em uma empresa de fast food de Santa Maria - RS. Revista de Administração da UFSM, Santa Maria, v. 5, n. 3, p. 525-538, 2012.

SANCHO, L. G. et al. Rotatividade na força de trabalho da rede municipal de saúde de Belo Horizonte, Minas Gerais: um estudo de caso. Revista Trabalho, Educação e Saúde, v. 9, n. 3, p. 43 I-447, 20 I I. SCHEIN, E. H. Organizational psychology then and now: Some observations. Annual Review of Organizational Psychology and Organizational Behavior, v. 2, p. I-19, 2015.

SILVA, R. S.; CAPPELLOZZA,A.; COSTA, L. V. O impacto do suporte organizacional e do comprometimento afetivo sobre a rotatividade. Revista de Administração IMED, v. 4, n. 3, p. 3 |4-329, 20 |4. STEEL, R. P.; LOUNSBURY, J.W.Turnover process models: Review and synthesis of a conceptual literatu- re. Human Resource Management Review, v. 19, p. 27I-282, 2009.

VASCONCELLOS, V. C.; NEIVA, V. R. Avaliação de futuro profissional e sua relação com bem-estar no trabalho e intenção de desligamento. Gestão \& Planejamento, v. I5, n. 2, p. 4l0-427, 2014. Disponível em: <www.spell.org.br/documentos/download/33827>

VIEIRA, R. G. Estudo da rotatividade de pessoal em universidade pública estadual. Revista de Ciências Gerenciais, v. 15, n. 22, p. 39-50, 2011.

\section{REFERÊNCIAS}

AGAPITO, P. R.; POLIZZI, A. P. F.; SIQUEIRA, M. M. M. Bem-estar no trabalho e percepção de sucesso na carreira como antecedentes de intenção de rotatividade. Revista de Administração Mackenzie, v. 16, n. 6, Edição Especial, p. 7I-93, 2015.

ANSELMI, M. L.; ANGERAMI, E. L. S.; GOMES, E. L. R. Rotatividade dos trabalhadores de enfermagem nos hospitais do Município de Ribeirão Preto. Revista Panamericana de Salud Pública, v. 2, n. I, p. 44-50, 1997.

BEZERRA, A. L. Q. O significado da rotatividade de pessoal numa instituição de saúde privada. Revista Brasileira de Enfermagem, v. 50, n. I, p. 107-120, 1997.

BORGES-ANDRADE, J. A.; PAGOTTO, C.P. O estado da arte da pesquisa brasileira em Psicologia do Trabalho e Organizacional. Psicologia: Teoria e Pesquisa, v. 26, número especial, p. 37-50, 2010.

BRAYFIELD, A. H.; CROCKETT,W. H. Employee attitudes and employee performance. Psychological Bulletin, v. 52, n. 05, p. 396-424, 1955.

CAMPOS, C. V. A.; MALIK, A. M. Satisfação no trabalho e rotativida- 
de dos médicos do Programa de Saúde da Família. Revista de Administração Pública, v. 42, n. 2 , p. 347-368, 2008.

CARRARA, T. M. P.; NUNES, S. C.; SARSUR, A. M. Fatores de retenção, permanência e desligamento de talentos e de performers. Revista de Administração, Contabilidade e Economia, v. 13, n. 3, p. III9-II48, 20|4. Disponível em: <http://editora.unoesc.edu. br/index.php/race>

CAVAZOTTE, F. S. C. N.; OLIVEIRA, L. B.; MIRANDA, L. C. Desigualdade de gênero no trabalho: reflexos nas atitudes das mulheres e em sua intenção de deixar a empresa. Revista de Administração da USP, v. 45, n. I, p. 70-83, 2010.

DIEESE - DEPARTAMENTO INTERSINDICAL DE ESTATÍSTICA E ESTUDOS SOCIOECONÔMICOS. Rotatividade e políticas públicas para o mercado de trabalho, São Paulo, 20I4. Disponível em: <http://goo.gl//Z3×0b>

FERREIRA, L. C. M.; ALMEIDA, C. B. A. Rotatividade de funcionários e desempenho organizacional: um estudo no comércio brasileiro. Brazilian Administration Review, v. I2, n. 4, p. 28-6I, 2015.

FERREIRA, M. C.; FREIRE, O. N. Carga de trabalho e rotatividade na função de frentista. Revista de Administração Contemporânea, v. 5, n. 2, p. I75-200, 200 I.

FERREIRA, M. L. C. B.; SIQUEIRA, M. M. M. Antecedentes de intenção de rotatividade: estudo de um modelo psicossocial. Organizações em Contexto, v. I, n. 2, p. 47-67, 2005.

HARKINS, P. J. Why employees stay or go. Workforce, v. 77, n. 10, p. 74-78, 1998.

HEAVEY, A. L.; HOLWERDA, J. A.; HAUSKNECHT, J. P. Causes and consequences of collective turno- ver: A meta-analytic review. Journal of Applied Psychology, v. 98 , n. 3, p. 4I2-453, 2013.

HERZBERG, F. et al. Job attitudes: review of research and opinion. Industrial and Labor Relations Review, Psychological Service of Pittsburgh, Pittsburgh, 1957.

HOLANDA, F. L.; CUNHA, I. C. K. O. Tempo de permanência de enfermeiros em um hospital-escola e valores monetários despendidos nos processos de admissão, desligamento e provimento de novo profissional. Revista Latino-americana de Enfermagem, v. I3, n. 5, p. 642-647, 2005.

HOM, P.W. et al. One hundred years of employee turnover theory and research. Journal of Applied Psychology, v. 102, n. 3, p. 530545, 2017.

IWAMOTO, H. H.; ANSELMI, M. L. Rotatividade dos trabalhadores de enfermagem nos hospitais do município de Uberaba, Minas Gerais. Revista Gaúcha de Enfermagem, v. 27, n. 3, p. 443-453, 2006.

KEVIN, M. M.;JOAN, L. C.;ADRIAN,J. W. Organizational change and employee turnover. Personnel Review, v. 33, n. 2, p. 161-166, 2004.

LEE, T. W., \& MITCHELL, T. R. An alternative approach: The unfolding model of voluntary employee turnover. Academy of Management Review, v. 19, n. I, p. 5 I-89, 1994.

LOPES, E. L.; MORETTI, S. L. A.; ALEJANDRO,T. B.Avaliação de justiça e intenção de turnover em equipes de vendas: teste de um modelo teórico. Revista de Administração de Empresas, v. 5 I, n. 6 , p. 553-567, 2011 .

MACIEL, C. O.; CAMARGO, C. Sobrequalificação no trabalho e sua influência sobre atitudes e comportamentos. Revista de Admi- nistração Contemporânea, v. 17, n. 2, p. 218-238, 2013.

MARGOTO,J. B.; BEHR, R. R.; PAULA, A. P. P. Eu me demito! Evidências da racionalidade substantiva nas decisões de desligamento em organizações. Organização \& Sociedade, v. 17 , n. 52, p. $115-135$, 2010.

MEDEIROS, C. R. G. et al. A rotatividade de enfermeiros e médicos: um impasse na implementação da Estratégia de Saúde da Família. Ciência \& Saúde Coletiva, v. 15, n. supl. I, p. I52I-I53।, 20 I0.

MÜNDERLEIN, M.;YBEMA, J. F.; KOSTER, F. Happily ever after? Explaining turnover and retirement intentions of older workers in The Netherlands. Career Development International, v. 18, n. 6 , p. 548-568, 2013.

NERY, P. F. O que é rotatividade (e por que é um problema)? Brasil, Economia e Governo, 15 abr. 20I5. Disponível em: <http:// www.brasil-economia-governo. org.br/2015/04/15/o-que-e-rotatividade-e-por-que-e-um-proble$\mathrm{ma} />$

NOMURA, F. H.; GAIDZINSKI, R. R. Rotatividade da equipe de enfermagem: estudo em hospital-escola. Revista Latino-americana de Enfermagem, v. 13, n. 5, p. 648-653, 2005.

OLIVEIRA, L. B.; CAVAZOTTE, F.S.C. N.; PACIELLO, R. R. Antecedentes e consequências dos conflitos entre trabalho e família. Revista de Administração Contemporânea, v. 17, n. 4, p. 418-437, 2013. Disponível em: <http:// dx.doi.org/10.1590/s।415655520|3000400003>

OLIVEIRA, L. B.; HONÓRIO, S. R. F. S. Atração e desligamento voluntário de jovens empregados: um estudo de caso no setor jornalístico. Revista de Administração 
da USP, v. 49, n. 4, p. 7/4-730, 2014.

ONGORI, H. A review of the literature on employee turnover. African Journal of Business Management, v. I, n. 2, p. 49-54, 2007.

PIERANTONI, C. R. et al. Rotatividade da força de trabalho médica no Brasil. Saúde em Debate, v. 39, n. 106, p. 637-647, 2015.

POCHMANN, M. O trabalho na crise econômica no Brasil: primeiros sinais. Estudos Avançados, São Paulo, v. 23, n. 66, p. 4I-52, 2009.

PRAÇA, S.; FREITAS, A.; HOEPERS, B. A rotatividade dos servidores de confiança no Governo Federal Brasileiro, 2010/20II. Novos Estudos, v. 94, p. 91-107, 2012.

PRICE, J. L. The study of turnover. lowa: State University Press, 1977. ROBBINS, S. P.; JUDGE, T.A.; SOBRAL, F. Comportamento organizacional. Teoria e prática no contexto brasileiro. $14^{\mathrm{a}}$ ed. São
Paulo: Pearson Prentice Hall, 2010.

ROE, R. A. Industrial, work and organizational psychology in Europe. In: ONES, D. S. et al. (Orgs.). The SAGE handbook of industrial, work \& organizational psychology, v. 3. London: SAGE, 20I8, p. 46-75.

ROSA, M. S.; IBDAIWI, T. K. Fatores responsáveis pelo turnover em uma empresa de fast food de Santa Maria - RS. Revista de Administração da UFSM, Santa Maria, v. 5, n. 3, p. 525-538, 2012. SANCHO, L. G. et al. Rotatividade na força de trabalho da rede municipal de saúde de Belo Horizonte, Minas Gerais: um estudo de caso. Revista Trabalho, Educação e Saúde, v. 9, n. 3, p. 431-447, 20 II. SCHEIN, E. H. Organizational psychology then and now: Some observations. Annual Review of Organizational Psychology and Organizational Behavior, v. 2,
P. I-19, 2015.

SILVA, R. S.; CAPPELLOZZA,A.; COS-

TA, L. V. O impacto do suporte organizacional e do comprometimento afetivo sobre a rotatividade. Revista de Administração IMED, v. 4, n. 3, p. 3।4-329, 2014.

STEEL, R. P.; LOUNSBURY, J.W. Turnover process models: Review and synthesis of a conceptual literature. Human Resource Management Review, v. 19, p. 27I-282, 2009.

VASCONCELLOS, V. C.; NEIVA, V. R. Avaliação de futuro profissional e sua relação com bem-estar no trabalho e intenção de desligamento. Gestão \& Planejamento, v. 15 , n. 2, p. 4I0-427, 20I4. Disponível em: <www.spell.org.br/documentos/download/33827>

VIEIRA, R. G. Estudo da rotatividade de pessoal em universidade pública estadual. Revista de Ciências Gerenciais, v. 15, n. 22, p. 39-50, 201 I. 